\title{
Dynamics and Lubrication Problem Analysis of Main Bearings for IC Engines Based on Coupling between a Crankshaft and a Flexible Whole Engine Block
}

\author{
Y. Rozhdestvenskya, N. Khozeniuk ${ }^{a}$, S. Surovtsev ${ }^{a}$ \\ a South Ural State University (National Research University), Lenin av., 76, Chelyabinsk, Russia.
}

Keywords:

Main bearing

Lubricant

Crankshaft

Crankcase

Elastic deformation

Internal combustion engine

Corresponding author:

Nadezhda Khozeniuk South Ural State University

(National Research University),

Lenin av., 76, Chelyabinsk, Russia.

E-mail: khozeniukna@susu.ru

\begin{abstract}
A B S T R A C T
The article presents the solution to the interconnected problem of main bearings dynamics for the forced internal combustion (IC) engine. For the crankshaft main bearings system of the (IC) engines it is necessary to consider the cross-coupling effect of the tribounits arising from elastic links of bearings and journals (by means of an engine crankcase and a crankshaft). The technique is based on the iterative scheme of the solution of four tasks given above. It analyzes not only the influence of macrogeometry parameters of each main bearing and the influence of non-Newtonian properties of lubricant, but also elastic characteristics of a crankshaft and crankcase and supports displacements caused by the thermal deformation of an engine crankcase. The influence of technological coaxiality tolerance for bearings and necks of a crankshaft is also estimated. The modeling results of two types of engines are compared to various design of a crankcase. The research shows the necessity of applying the integrated approaches which allow considering simultaneously both the features of autonomous bearings and many facts of their interaction.
\end{abstract}

(c) 2018 Published by Faculty of Engineering

\section{INTRODUCTION}

Performance assurance of the hydrodynamic tribosystem is one of the basic problems in the creation and operational development of internal combustion engines design. Mainly it is caused by complexity and interconnectivity of the processes and factors defining the reliability of the fluid friction units. For the performance assurance of the hydrodynamic tribosystem it is necessary to take into account the following data: geometry of the tribounits, macro- and micro geometry of the friction surfaces, velocity and loading parameters, viscosity-temperature and rheological properties of the liquid lubricant dividing the complex loaded surfaces of the friction. Together with these parameters considered in the autonomous tribounits simulation, for the system of crankshaft main bearings of the internal combustion engines it is necessary to consider the cross-coupling effect of the tribounits arising from elastic links of bearings and journals (by means of an engine crankcase and a crankshaft). 
Moreover, the factors determining a relative position of its journals and bearings influence significantly the reliability of the main bearings system. Among these factors one should mention technology and thermal factors. The technology factors are correlated with coaxiality tolerance of the holes into the crankcases and a run-out tolerance of the crankshaft journals. Modeling the influence of thermal stress state of a crankcase on hydromechanical characteristics of main bearings of diesel engines requires a detailed description of thermal fields. This description requires modeling a heat emission in cylinders and liquid flows in the cooling system of the engine heads and crankcases.

The existing methods of modeling the interconnected processes of lubricant flow in thin liquid layers and nonlinear dynamics for a system of "a crankshaft - lubricating films - a crankcase" are reduced to the separate subtasks solution [1-3].

Such methods are mostly used for heavy-loaded autonomous (isolated) hydrodynamic bearings. However, they do not allow to estimate the influence of design and technological factors such as different values of elastic compliances of crankshaft supports, misalignments of journals and main bearings and so on.

The fullest model was suggested by S. M. Zakharov [4], D. Bonneau et al. [5-9]. The technique [4] considered the deviations of the necks of the crankshaft and the angular compliances of the crankshaft supports, but for obtaining the results the authors were compelled to apply an approximation method (Holland's method). The complete models [9] simultaneously consider the bearings as a whole with their relative displacements under the deformation effect of the engine block and the crank shaft, but authors didn't analyze influence of admissions on coaxiality of pins of a shaft, other technological and thermal factors on operability of main bearings system.

\section{METHOD DESCRIPTION}

The efficiency of hydrodynamic tribounits can be estimated by calculating the standard set of hydromechanical characteristics (HMC) in order to predict the fatigue durability and wear resistance of bearing antifriction layers, friction losses, thermal loading of tribosystems, and solve the problem of optimizing the design parameters [10-14]. The most important HMC for main bearings are: instant values of the minimum film thickness $h_{\min }(t)$ and the maximum hydrodynamic pressure $p_{\max (t)}$ of a lubricant layer, and also their extremes $\inf h_{\min }$, $\sup p_{\max }$ and averages $h_{\min }^{*}, p_{\max }^{*}$ magnitudes per cycle of loading; effective temperature of a lubricating layer $T^{*}$, instant and average power losses to friction $N(t), N^{*}$ lubricant flow rates $Q(t), Q^{*}$.

HMC determination of main bearings system for IC engine is based on the solution of four interrelated problems: 1) the dynamics of a journal on the lubricant layer under the influence of non-steady external forces and reactions of the lubricant layer; 2) the hydrodynamic theory of lubrication to determine the pressure distribution in the lubricant film taking into account the design features of tribounits and the rheological properties of the oil; 3 ) a determination of the thermal state of the bearing for the correction of the lubricant viscosity; 4) elastic model for determination the interrelation between elastic compliance of crankshaft and crankcase and bearing reactions

\subsection{Dynamic subtask}

The position of each central of crankshaft necks $X^{j}(\tau), Y^{j}(\tau), \alpha^{j}(\tau), \beta^{j}(\tau), j=1, . ., n+1$ (where $n$ is number of cranked port of shaft) defined by the decision of the dynamic equation system (the subscript $j$ isn't specified):

$$
\left\{\begin{array}{l}
m \ddot{\bar{U}}=\bar{F}(\bar{U}, \dot{\bar{U}}, \bar{\gamma}, \dot{\bar{\gamma}}, \tau)+\bar{R}(\bar{U}, \dot{\bar{U}}, \bar{\gamma}, \dot{\bar{\gamma}}, \tau) \\
J \ddot{\bar{\gamma}}=\bar{M}_{\mathrm{F}}(\bar{U}, \dot{\bar{U}}, \bar{\gamma}, \dot{\bar{\gamma}}, \tau)+ \\
\bar{M}_{\mathrm{R}}(\overline{\bar{U}}, \dot{\bar{U}}, \bar{\gamma}, \dot{\bar{\gamma}}, \tau)+\bar{M}_{\mathrm{G}}(\bar{U}, \dot{\bar{U}}, \bar{\gamma}, \dot{\bar{\gamma}}, \tau)
\end{array}\right.
$$

where $\bar{U}=\{X, Y\}, \quad \bar{\gamma}=\{\alpha, \beta\}=\{-\gamma \cos \varepsilon, \gamma \sin \varepsilon\}$, $\dot{\bar{U}}, \dot{\bar{\gamma}}, \ddot{\bar{U}}, \ddot{\bar{\gamma}}$ are vectors of linear and angular coordinates, velocities and accelerations of the journals respectively; $\gamma$ is the skewed angle between the neck and bearing axis; $\varepsilon$ is the angle 
between the skewed and coordinated planes; $m, J$ are the journal inertial characteristics; $\bar{F}=\left\{\tilde{F}_{\mathrm{X}}, \tilde{F}_{\mathrm{Y}}\right\}, \bar{M}_{\mathrm{F}}=\left\{\tilde{M}_{\mathrm{X}}, \tilde{M}_{\mathrm{Y}}\right\}$ are forces and moments acting on the bearing (they are defined by solving the system (5); $\bar{R}, \bar{M}_{\mathrm{R}}$ are the resultant vectors of forces and moments received by integration of the Reynolds equation for the lubricant pressure; $\bar{M}_{\mathrm{G}}$ is the gyroscopic torque. Unlike autonomous bearing, the vectors for nonautonomous bearings system depends on elastic characteristics of all supports and thus coordinates and accelerations of all crankshaft journals centres.

\subsection{Hydrodynamics subtask}

For the definition of a hydrodynamic reaction of each bearing lubricated by non-Newtonian liquid it is necessary to know a hydrodynamic pressure distribution in a thin lubricant layer $p(\varphi, z, \tau)$. This function is obtained by solving Reynolds' differential equation $[2,15,16]$ :

$$
\begin{aligned}
& \frac{\partial}{\partial \varphi}\left[\bar{h}^{k+2}\left(\bar{\varphi}_{2}-\frac{\bar{\varphi}_{1}^{2}}{\bar{\varphi}_{0}}\right) \rho \frac{\partial \bar{p}}{\partial \varphi}\right]+ \\
& +\frac{\partial}{\partial z}\left[\bar{h}^{k+2}\left(\bar{\varphi}_{2}-\frac{\bar{\varphi}_{1}^{2}}{\bar{\varphi}_{0}}\right) \rho \frac{\partial \bar{p}}{\partial z}\right]= \\
& =\frac{\partial}{\partial \varphi}\left[\bar{\omega} \bar{\rho}\left(1-\frac{\bar{\varphi}_{1}}{\bar{\varphi}_{0}}\right)\right]+\frac{\partial}{\partial \tau}(\bar{\rho} \bar{h}),
\end{aligned}
$$

where $\bar{\rho}$ is lubricant density; $\bar{p}=\left(p-p_{a}\right) \psi^{2} / \mu_{0} \omega_{0} h$ are a non-dimensional hydrodynamic pressure and film thickness respectively; $\quad p, p_{\mathrm{a}}$ are a dimensional hydrodynamic pressure and the atmospheric pressure value; $\psi, \omega$ are relative values of a bearing clearance and angular velocity; $\bar{Z}$ is a non-dimensional coordinate in the direction of a bearing width; $\varphi$ is an angular bearing coordinate; $k$ is an index characterizing the degree of non-newtonian behavior of a lubricant; $\quad \bar{\varphi}_{k}=\int_{\bar{y}_{1}}^{\bar{y}_{2}} \bar{y}^{k} / \bar{\mu}^{*} d \bar{y}, \quad k=0,1,2 ; \bar{y} \quad$ is a non-dimensional coordinate on the frictional surface normal; $\bar{\mu}^{*}$ is a non-dimensional value of viscosity which depends of viscosity versus shear rate, pressure and temperature:

$$
\bar{\mu}^{*}=(I)^{(k-1) / 2} \times C_{1} \times e^{\left(C_{2} /\left(T_{\mathrm{e}}+C_{3}\right)\right)+\beta\left(T_{\mathrm{e}}\right) p}
$$

where $\bar{I}_{2}=\left(\partial \bar{V}_{\mathrm{x}} / \partial \bar{y}\right)^{2}+\left(\partial \bar{V}_{\mathrm{z}} / \partial \bar{y}\right)^{2}$ is the second invariant of the shear rate; $T_{\mathrm{e}}$ is the temperature of the lubricant layer; $C_{1}, C_{2}, C_{3}$ are the constants, which are the empirical characteristics of the lubricant; $\beta\left(T_{\mathrm{e}}\right)$ is a piezoelectric coefficient of viscosity which depends on the temperature and chemical composition of the lubricants. The empirical procedure for determining the characteristics of a lubricant is proved in [17].

The dimensional function of the film thickness taken into account the skewness of axes is:

$$
\begin{aligned}
& h\left(\varphi, Z_{1}, \tau\right)=h^{*}\left(\varphi, Z_{1}\right)- \\
& -e(\tau) \cos (\varphi-\delta(\tau))+ \\
& +Z_{1} \frac{2 S(\tau)}{B} \cos (\varphi-\varepsilon(\tau))+L_{\mathrm{p}}
\end{aligned}
$$

where $e(\tau)$ is the displacement of the journal mass centres relative to the bearing; $\delta(\tau)$ is the angle taking into account the skewness of axes of the bearing and the journal; $S(\tau)$ is the distance between the geometric centres of the journal and the bearing at the ends of the tribounit; $B$ is the bearing width, $Z_{1} \in[-B / 2 ; B / 2] ; h^{*}\left(\varphi, Z_{1}\right)$ is the bearing layer thickness with non-ideal geometry at the central journal position; $L_{\mathrm{p}}$ is elastic deformations of bearing.

At integration of the equation (2) the StieberSwift boundary conditions are used.

The lubricant thermal state (1-4) is based on the isothermal approach. It assumes that the calculated current temperature is the same at the all points of the lubricant film. This temperature is a highly inertial parameter and it is determined by solving the bearing heat balance equation for correcting of the lubricant viscosity. The calculating method for the autonomous bearing is in more detail presented in work $[15,18]$.

\subsection{Elastic subtask}

The mechanical model presented on Fig. 1 is a statically indeterminate 3D beam system on an elastic foundation. Forces and moments, acting 
to the $j$-th bearing $\tilde{F}_{\mathrm{X}}^{j}(\tau), \tilde{F}_{\mathrm{Y}}^{j}(\tau), \tilde{M}_{\mathrm{X}}^{j}(\tau), \tilde{M}_{\mathrm{Y}}^{j}(\tau)$ are defined by redundant problem solving. The solution of this problem is based on equation of five moments:

$$
[\delta] \times\{M\}=\{R\}
$$

where $[\delta]$ is the band matrix of the influence coefficients

$\delta_{i j}=\delta_{i j}\left(K_{s, \mathrm{X}}^{\lambda, j=1, n}, K_{s, \mathrm{Y}}^{\lambda, j=1, n}, K_{\mathrm{L}, \mathrm{X}}^{\lambda, j=1, n}, K_{\mathrm{L}, \mathrm{Y}}^{\lambda, j=1, n}\right.$, $\left.K_{\mathrm{s}, \mathrm{X}}^{\varphi, j=1, n}, K_{\mathrm{s}, \mathrm{Y}}^{\varphi, j=1, n}, K_{\mathrm{L}, \mathrm{X}}^{\varphi, j=1, n}, K_{\mathrm{L}, \mathrm{Y}}^{\varphi, j=1, n}\right) ;\{M\}$ is the vector of unknown moments; $\{R\}$ is on the right part of Eq. (5), each vector entry is the deflection under external forces and moments $R_{i}=R_{i}\left(F_{\mathrm{X}}^{j=1, n,(s)}, F_{\mathrm{Y}}^{\lambda, j=1, n,(s)}, K_{\mathrm{s}, \mathrm{X}}^{\lambda, j=1, n}, K_{\mathrm{s}, \mathrm{Y}}^{\lambda, j=1, n}\right.$, $\left.K_{\mathrm{L}, \mathrm{X}}^{\lambda, j=1, n}, K_{\mathrm{L}, \mathrm{Y}}^{\lambda, j=1, n}, \Delta_{\text {case }}, \Delta_{\text {necks }}\right), \quad \Delta_{\text {case, }} \Delta_{\text {necks }} \quad$ are misalignments of necks and main bearings.

Usually these misalignments are correlated with technology and thermal factors. The technological misalignments are caused by a coaxiality tolerance of the holes into the crankcase and a run-out tolerance of the crankshaft journals. The technique of thermal state definition is presented in works $[19,20]$.

Identification procedure of the elastic properties of the shaft and linear $K_{\mathrm{s}, \mathrm{X}}^{\lambda, j}, K_{\mathrm{s}, \mathrm{Y}}^{\lambda, j}$ and angular $K_{\mathrm{s}, \mathrm{X}}^{\varphi, j}, K_{\mathrm{s}, \mathrm{Y}}^{\varphi, j}$ compliances is presented in work [21].
Influence of the lubricant layers dividing friction surfaces of the main bearing journals of a crankshaft and a crankcase of the IC engine is modelled by means of non-linear elastic elements with the compliances $K_{\mathrm{L}, \mathrm{X}}^{\lambda, j}(\tau), K_{\mathrm{L}, \mathrm{Y}}^{\lambda, j}(\tau)$, $K_{\mathrm{L}, \mathrm{X}}^{\varphi, j}(\tau), K_{\mathrm{L}, \mathrm{Y}}^{\varphi, j}(\tau)$.

These compliances depend on the lubricant layers thickness which varies with time because the centres of the journals move on some trajectories under the loads $F^{i,(s)}$, where $i$ is number of the cranked port of shaft, $s=1, . ., 7$ is number of the external force (see Fig. 1). Instant values of the compliances can be defined by the expressions:

$$
\begin{gathered}
K_{\mathrm{L}, \mathrm{X}}^{\lambda, j}(\tau)=X^{j}(\tau) / \tilde{F}_{\mathrm{X}}^{j}(\tau), \\
K_{\mathrm{L}, \mathrm{Y}}^{\lambda, j}(\tau)=Y^{j}(\tau) / \tilde{F}_{\mathrm{Y}}^{j}(\tau), \\
K_{\mathrm{L}, \mathrm{X}}^{\varphi, j}(\tau)=\alpha^{j}(\tau) / \tilde{M}_{\mathrm{X}}^{j}(\tau), \\
K_{\mathrm{L}, \mathrm{Y}}^{\varphi, j}(\tau)=\beta^{j}(\tau) / \tilde{M}_{\mathrm{Y}}^{j}(\tau),
\end{gathered}
$$

where $\tilde{F}_{\mathrm{X}}^{j}(\tau), \tilde{F}_{\mathrm{Y}}^{j}(\tau), \tilde{M}_{\mathrm{X}}^{j}(\tau), \tilde{M}_{\mathrm{Y}}^{j}(\tau)$ are instant values of the forces and moments, acting to the $j$-th bearing; $X^{j}(\tau), Y^{j}(\tau), \alpha^{j}(\tau), \beta^{j}(\tau)$ are the positions of the centre of the $j$-th main bearing journal of the crankshaft.

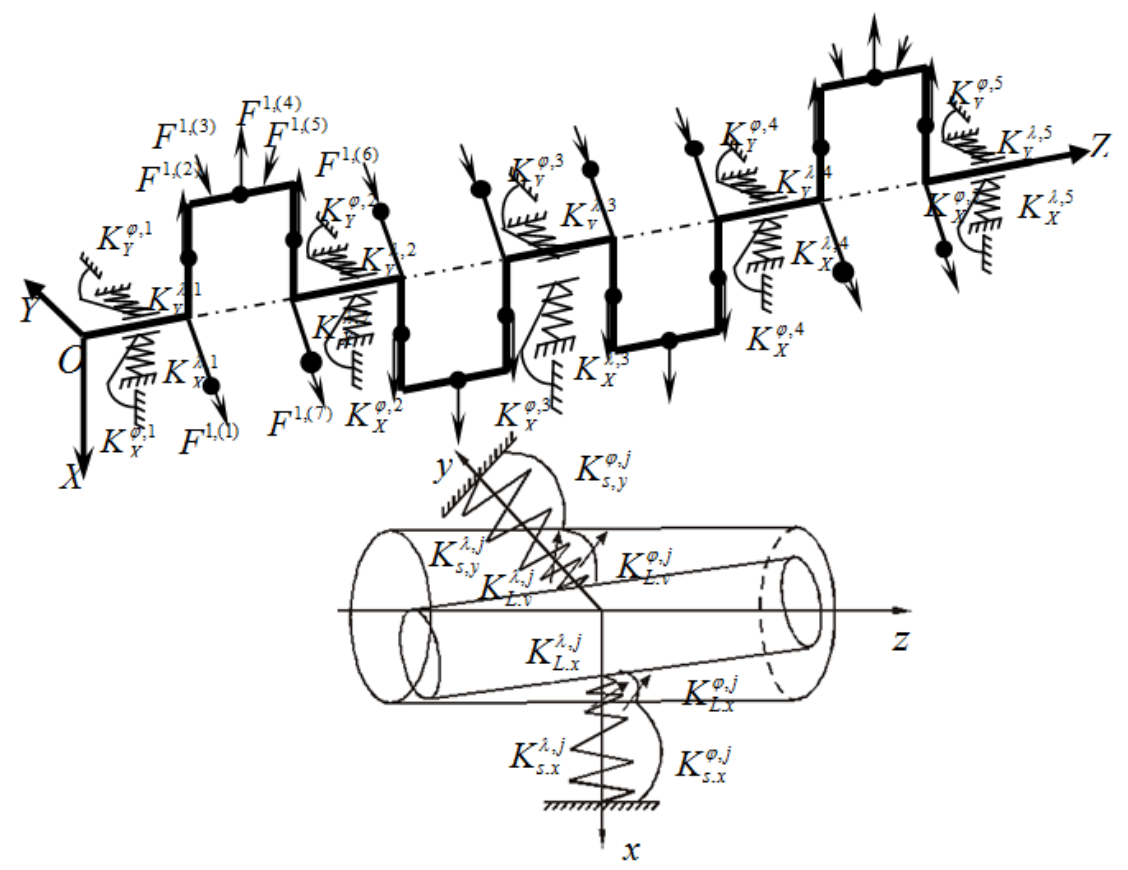

Fig. 1. Dynamic models of the crankshaft and bearing. 
At the performance evaluation of nonautonomous main bearings (main bearings system), the determining methods of the autonomous bearings HMC are combined by an iterative process with the calculation of the loads. The iterative process is based on the continuous scheme of the multisupporting crankshaft on the elastic foundation. The elastic structural properties (a crankshaft and a crankcase), the misalignment of the journals and the main bearings, the nonlinear damping properties of the lubricant layers can be considered in the calculation of acting loads. For the solution to this problem it is offered to use the iterative algorithm which requires consistent calculation of loads, acting on bearings, and trajectories of movement of the centers of their journals into bearings. For calculating loads not only gas and inertial parts are considered, but also elastic properties of supports and a shaft. They are defined by means of three-dimensional finite element models of the engine crankcase and crankshaft. The finite differences method by the multigrid technique for the Reynolds equation was applied for the definition of the main journals movement trajectories. The method allows to consider a dependence of viscosity on temperature, pressure and shear rate. In addition the scheme of oil supply in each bearing layer, macrogeometrical characteristics of friction surfaces and other parameters are taken into account.

\section{RESULTS}

The described method is applied to the calculations of the main bearings system of 4cylinder in-line and 6-cylinder in-line engines (cylinder bore is $13 \mathrm{~cm}$, stroke of piston is $15 \mathrm{~cm}$ ). Input dates are given in Fig. 2 and in Table 1.

Table 1. Input dates.

\begin{tabular}{|c|c|}
\hline Parameter & Value \\
\hline angular velocity of bearing, rad/sec & 219.0 \\
\hline main bearing diameter, $\mathrm{m}$ & 0.105 \\
\hline main bearing width, $\mathrm{m}$ & 0.035 \\
\hline main bearing clearance, $\mathrm{m}$ & 0.000103 \\
\hline oil feed hole diameter into the journal, $\mathrm{m}$ & 0.007 \\
\hline oil feed hole angle, deg. & 90,270 \\
\hline groove start angle at the bearing surface, deg & 100 \\
\hline groove finish angle at the bearing surface, deg & 260 \\
\hline
\end{tabular}

FEA models of the crankshaft and a crankcase for two engines (see Figs. 3-4) are used. The elastic compliance coefficients are given in Figs. 5-6.

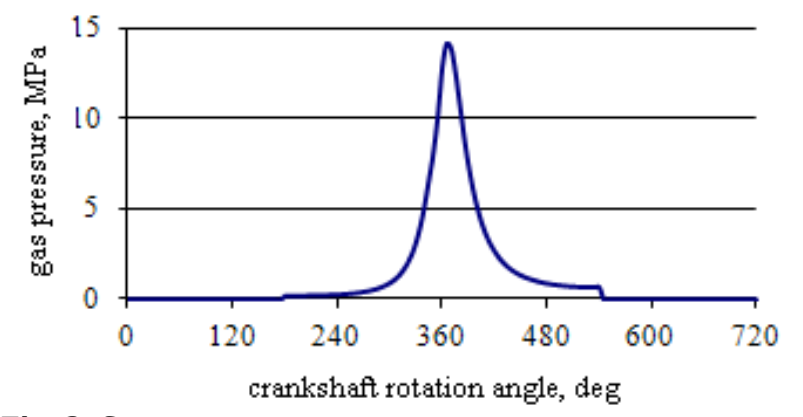

Fig. 2. Gas pressure.

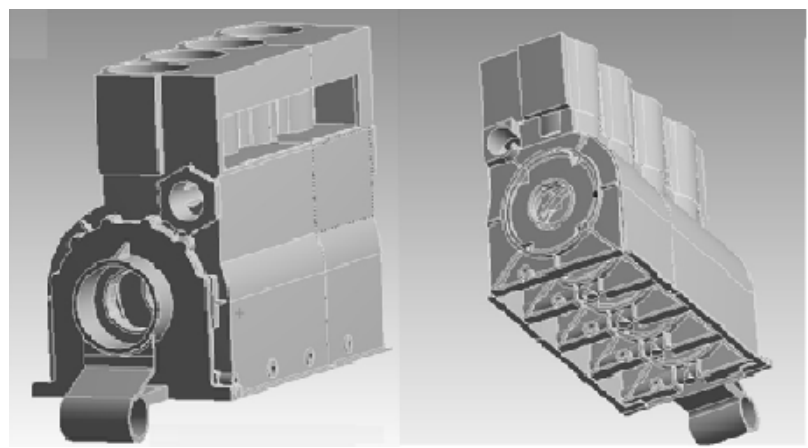

(a)

(b)

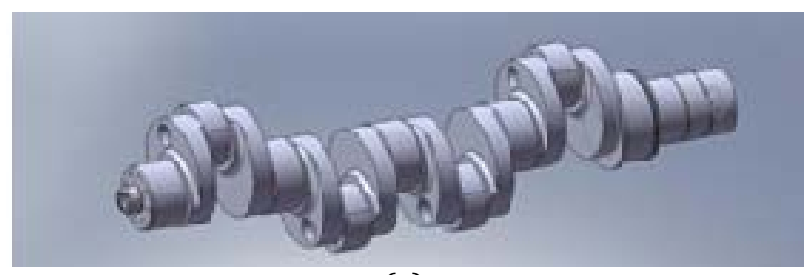

(c)

Fig. 3. Models of the crankcase and crankshaft of 4cylinder engine: model of the crankcase design No 2 (a), the crankcase design No 1 (b), the crankshaft model (c).

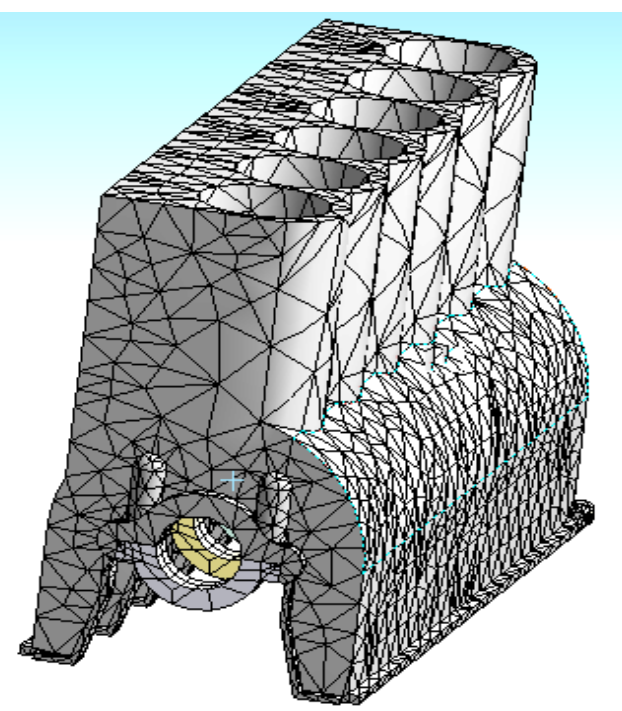

(a) 


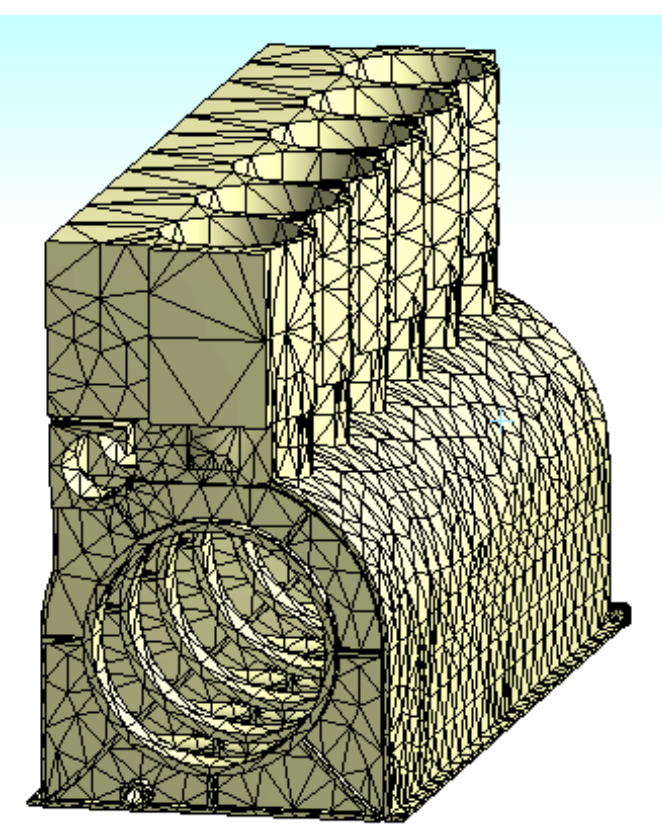

(b)

Fig. 4. Model of the crankcase of the 6-cylinder engine of design No 2 (a) and design No 1 (b).

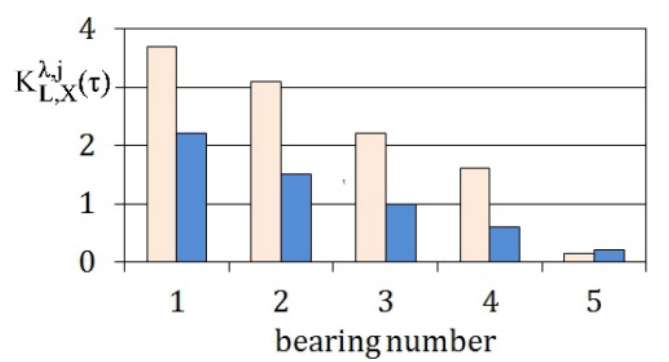

(a)

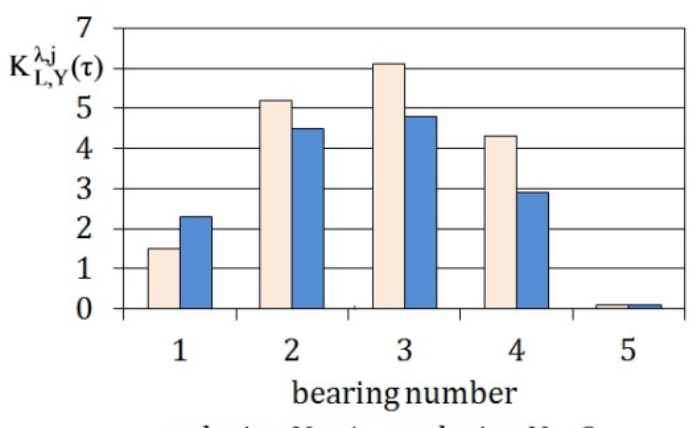

$\square$ design No. $1 \quad \square$ design No. 2

(b)

Fig. 5. The elastic compliance coefficients $(\mu \mathrm{m} / \mathrm{kN})$ of the supports for the 4-cylinder engine for XOZ plane (a), YOZ plane (b).

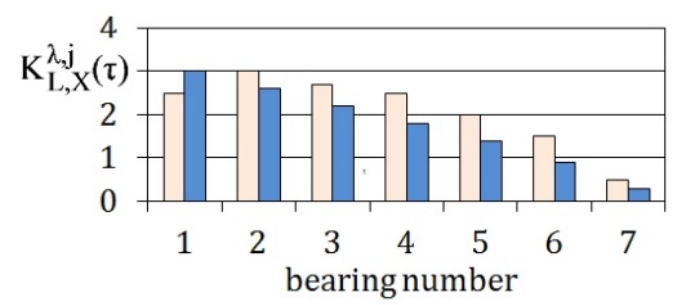

(a)

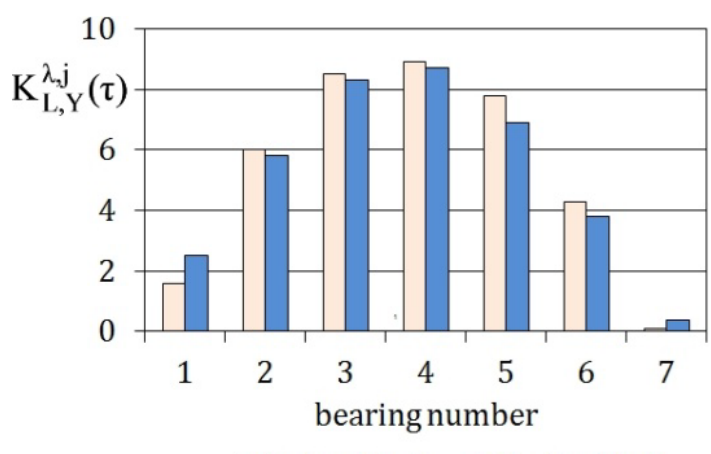

$\square$ design No. $1 \quad \square$ design No. 2

(b)

Fig. 6. The elastic compliance coefficients $(\mu \mathrm{m} / \mathrm{kN})$ of the supports for the 6-cylinder engine for $\mathrm{XOZ}$ plane (a), YOZ plane (b).

\subsection{Influence of elastic properties of supports}

Calculations of the main bearing systems for the two types of a crankcase of 4-cylinder and 6cylinder engines are made. The comparison of HMC is presented in Fig. 7 and in Table 2 (bearings and necks are coaxial). In this table is designated: 1) rigidly crankcase model; 2) crankcase of design No1; 3) crankcase of design No 2.

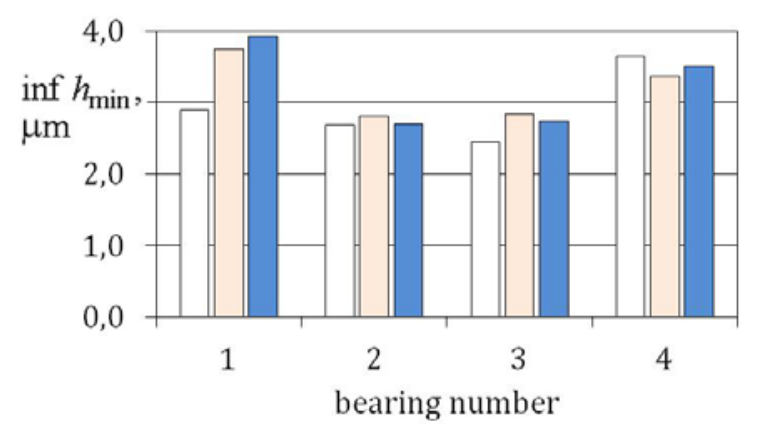

(a)

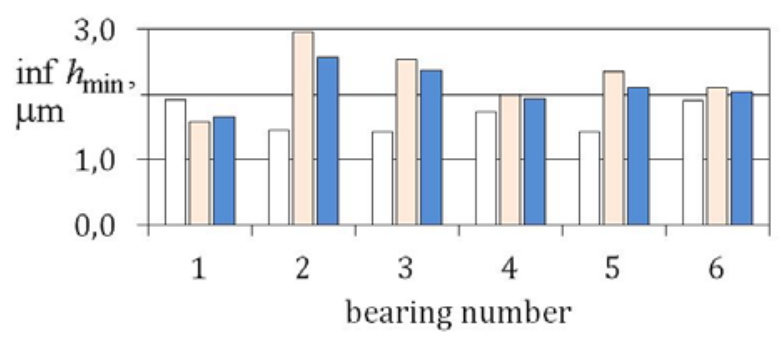

$\square$ rigidly crankcase model $\square$ design No $1 \square$ design No 2

(b)

Fig. 7. Comparison of HMC for 4-cylinder (a) and 6cylinder (b) engines (bearings and necks are coaxial).

If supports and necks are coaxial then the increase of elastic compliance coefficients of support most often positively influences the HMC of main bearings (see Fig. 7). Minimums of film thickness are $5-29 \%$ more (for a design No. 1) and $12-36$ 
$\%$ more (for a design No. 2) than for the case with absolutely rigid supports of a crankshaft.

Table 2. Hydromechanical characteristics of main bearings for the 4-cylinder engine.

\begin{tabular}{|c|c|c|c|c|c|c|}
\hline $\begin{array}{c}\text { Number } \\
\text { of } \\
\text { bearing }\end{array}$ & $\begin{array}{c}\inf h_{\min } \\
\mu \mathrm{m}\end{array}$ & $\begin{array}{c}\alpha_{h_{\min }}, \\
\operatorname{deg}\end{array}$ & $\begin{array}{c}h_{\min }^{*}, \\
\mu \mathrm{m}\end{array}$ & $\begin{array}{c}\sup p_{\max } \\
\text { MPa }\end{array}$ & $\begin{array}{l}p_{\text {max }} \\
\text { MPa }\end{array}$ & $\begin{array}{l}N^{*}, \\
\mathrm{~W}\end{array}$ \\
\hline \multirow{3}{*}{1} & 2.891) & 70 & 11.95 & 79 & 15 & 545 \\
\hline & $3.74^{2)}$ & 184 & 7.83 & 108 & 19 & 594 \\
\hline & $3.93^{3)}$ & 184 & 8.23 & 98 & 17 & 580 \\
\hline \multirow{3}{*}{2} & 2.68 & 243 & 9.10 & 225 & 40 & 651 \\
\hline & 2.81 & 15 & 11.53 & 156 & 25 & 584 \\
\hline & 2.69 & 15 & 12.98 & 180 & 29 & 585 \\
\hline \multirow{3}{*}{3} & 2.68 & 243 & 9.10 & 225 & 40 & 651 \\
\hline & 2.81 & 15 & 11.53 & 156 & 25 & 584 \\
\hline & 2.69 & 15 & 12.98 & 180 & 29 & 585 \\
\hline \multirow{3}{*}{4} & 3.64 & 609 & 11.00 & 148 & 26 & 588 \\
\hline & 3.37 & 15 & 12.99 & 130 & 26 & 559 \\
\hline & 3.51 & 15 & 12.95 & 121 & 25 & 560 \\
\hline
\end{tabular}

Comparison of the main bearings HMC for designs No. 1 and No. 2 of the engine crankcase between themselves shows that the twofold increase by elasticity does not lead to unambiguous change of values inf $h_{\min }$ : the film thickness of the second and third bearings increase by $5-4.5 \%$; however at the same time the film thickness of the first and fourth bearings decrease by 4-5\%. Apparently, the change of structural elasticity of a crankcase leads to the redistribution of the loadings acting on main bearings and corresponding change of HMC.

\subsection{Influence of displacement of crankshaft supports and necks}

The distribution of possible displacements of the crankshaft supports and necks were set on the basis of coaxiality tolerance of the holes into the crankcases and a run-out tolerance of the crankshaft journals according to technical documentation of the engine. Possible versions of displacements for design No 2 are presented in Fig. 8 (blue and green lines). The most dangerous displacement distributions are chosen by calculations of main bearings HMC considering crankcase elasticity and different combinations of supports and necks relocation (see Fig. 8, highlighted in red).
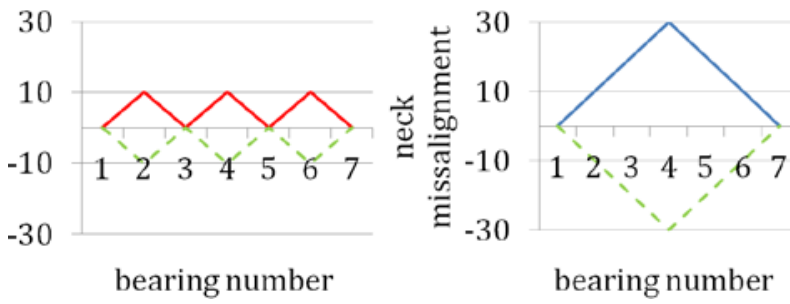

(a)
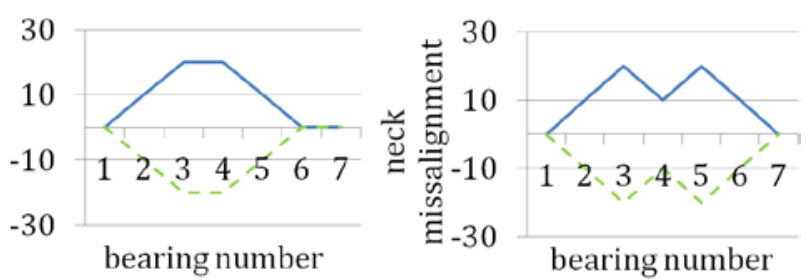

(b)

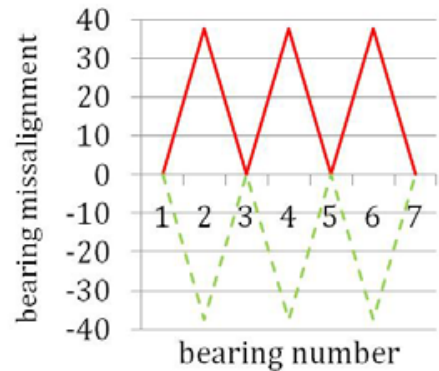

(c)

Fig. 8. Possible misalignment distribution for supports: dimensional tolerances for necks (a), (b) and coaxiality tolerance of the holes (c).

Modelling results of the main bearings system for the most dangerous misalignment distribution are presented in Figs. 9-10. The accounting of misalignment of the crankshaft supports and necks leads to decrease inf $h_{\min }$ by $20-80 \%$ for both designs of the crankcase for a 4-cylinder engine. At the same time for more elastic crankcase of design No. 1 the minimum thickness of the first (third) bearing is $6 \%$ (28\%) lower than rather similar value received for the crankcase of design No. 2. Values inf $h_{\min }$ are approximately at the same level for the second and fourth bearings. For the 6-cylinder engine the values inf $h_{\min }$ are reduced by 2.5 times.

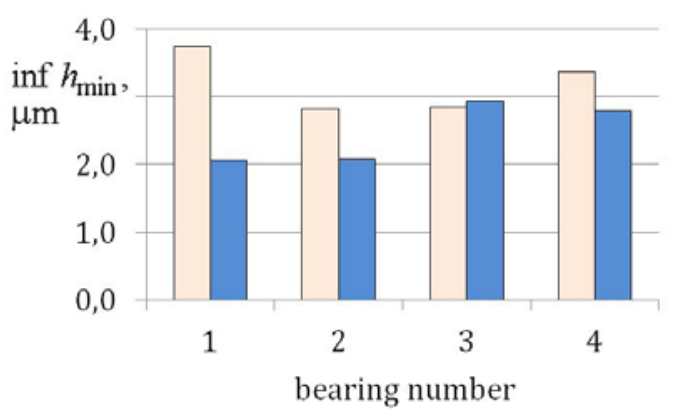

(a) 


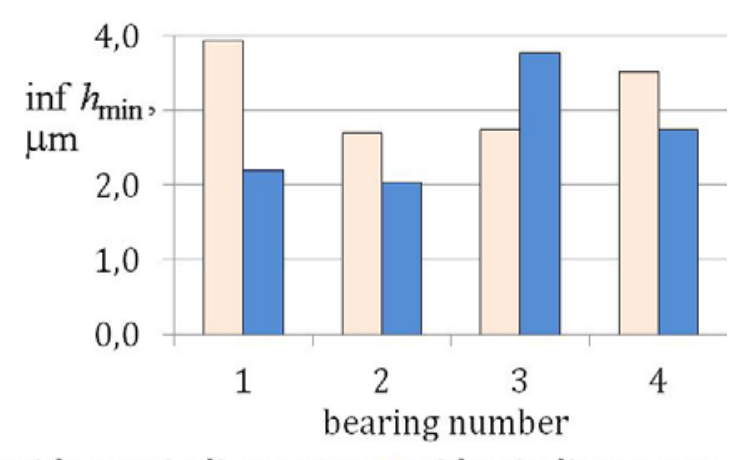

$\square$ without misalignments $\square$ with misalignments

(b)

Fig. 9. Comparison of HMC for a 4-cylinder engine: (a) design No 1 of crankcase, (b) design No 2 of crankcase.

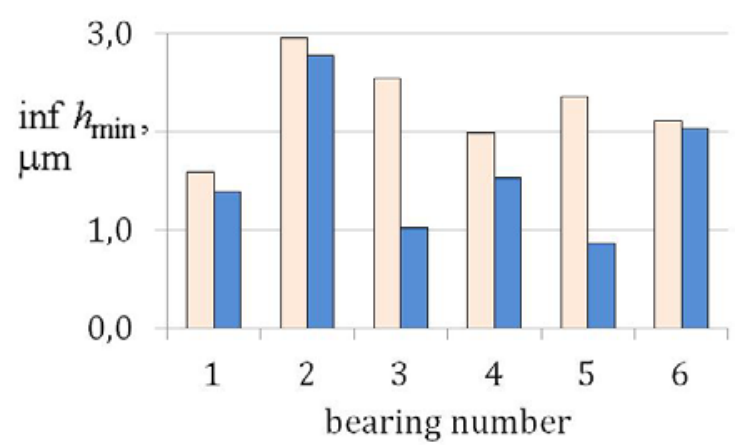

(a)

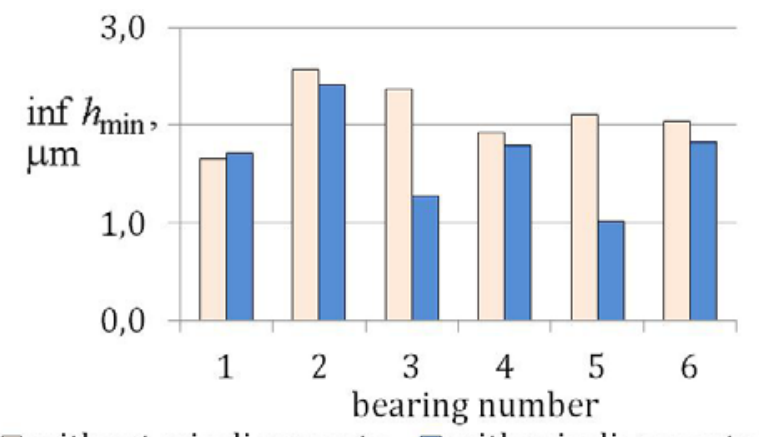

$\square$ without misalignments $\square$ with misalignments

(b)

Fig. 10. Comparison of HMC for the 6-cylinder engine: (a) design No 1 of crankcase, (b) design No 2 of crankcase.

It should be noted that the maximum difference of the supports displacement for design No. 1 is nearly 8 times higher than design No. 2. At the same time the change of the corresponding values $\inf h_{\min }$ is insignificant. It demonstrates desensitization to misalignment of crankshaft supports and necks by increasing the crankcase elasticity.

\subsection{Thermal effects}

The thermal field leads to crankcase deflection from the axis $\mathrm{OZ}$ and arouses a misalignment of the hole for bearings installation. The technique of a thermal state definition of a crankcase and the respective field of deformations is in detail considered in work $[19,20]$. The misalignments caused by various reasons are shown in table 3 and the modelling results are presented in Fig. 11, 12 for the 4th cylinder engine (rigidly crankcase model), were type 1 is bearings misalignments caused by thermal deformation, $\mu \mathrm{m}$; type 2 is technological misalignments for the bearings, $\mu \mathrm{m}$; type 3 is technological misalignments for the journals of the crankshaft, $\mu \mathrm{m}$.

Table 3. Comparison of values of the misalignments caused by various reasons, $\mu \mathrm{m}$.

\begin{tabular}{|c|c|c|c|c|c|}
\hline \multirow{2}{*}{$\begin{array}{c}\text { Types of } \\
\text { misalignment }\end{array}$} & \multicolumn{5}{|c|}{ Number of the crankshaft support } \\
\cline { 2 - 6 } & 1 & 2 & 3 & 4 & 5 \\
\hline Type 1 & -65 & 67 & 127 & 69 & -71 \\
\hline Type 2 & 0,0 & 10 & 0,0 & 10 & 0,0 \\
\hline Type 3 & 10 & -20 & 30 & -20 & 10 \\
\hline
\end{tabular}

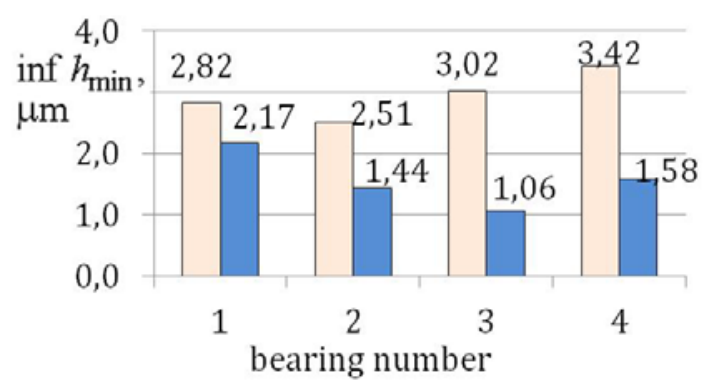

(a)

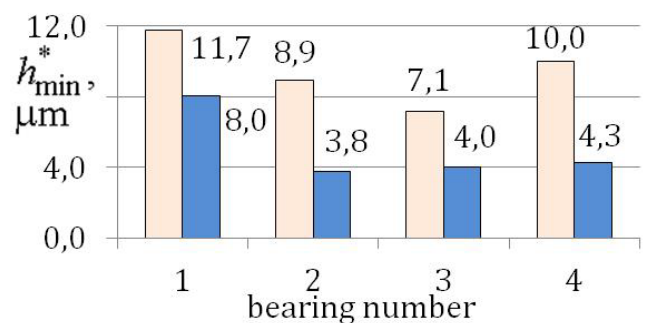

$\square$ without taking into account of thermal deformation of the crankcase

$\square$ type 1 of misaligment

(b)

Fig. 11. Influence of thermal deformation of a crankcase on the minimum (a) and average (b) film thickness of the main bearings system.

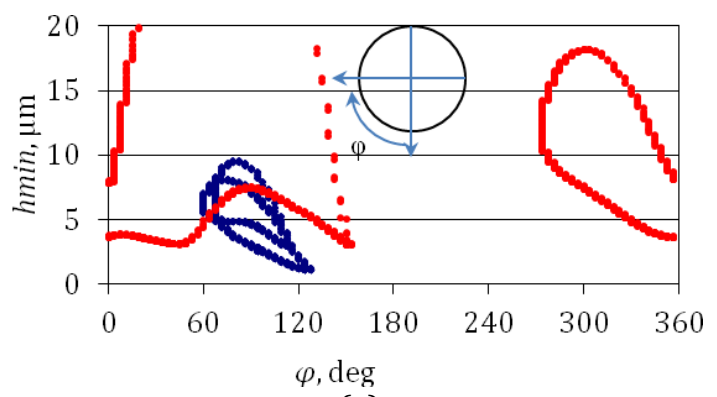

(a) 


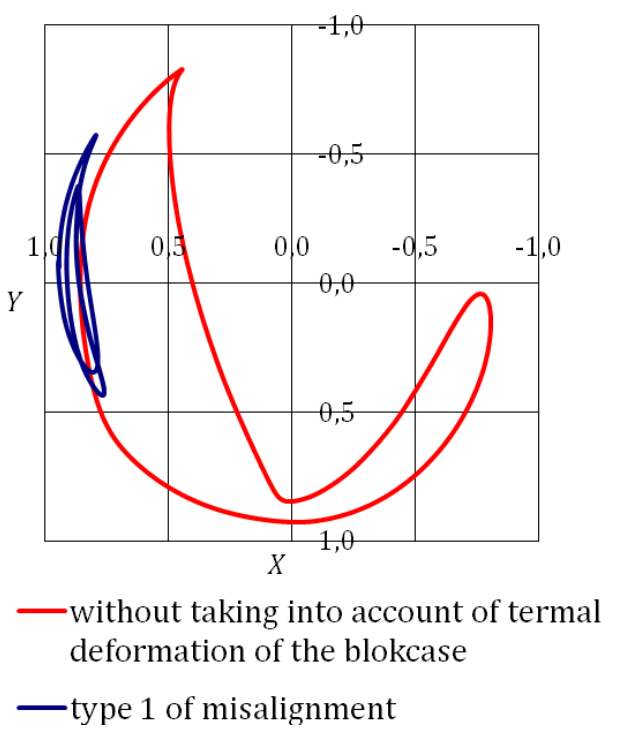

(b)

Fig. 12. Influence of thermal deformation of a crankcase on the distribution of minimum thickness (a) and the movement trajectory of the journal centre (b) for the third main bearing

Distributions of the minimum film thickness on the bearing surface and also a journal trajectory for the 3rd main bearing are shown in Fig. 12. It is obvious that misalignments from $\mathrm{OZ}$ rotation axis significantly influence the performance assurance of the main bearings system.

\section{CONCLUSION}

The research shows the necessity of applying the integrated approaches which allow to consider simultaneously both the features of autonomous bearings and many facts of their interaction.

\section{Acknowledgement}

South Ural State University is grateful for financial support of the Ministry of Education and Science of the Russian Federation (grant No 9.7881.2017/8.9).

\section{REFERENCES}

[1] K.P. Oh, P.K. Goenka, The elastohydrodynamic solution of the journal bearing under dynamic loading, Journal of Tribology, vol. 107, iss. 3, pp. 389-394, 1985, doi: 10.1115/1.3261088

[2] R.S. Paranjpe, S.I. Tseregounis, M.B. Viola, Comparison between theoretical calculations and oil film thickness measurements using the total capacitance method for crankshaft bearings in a firing engine, Tribology Transaction, vol. 43 , iss. 3 , pp. $345-356,2000$, doi: $10.1080 / 10402000008982350$

[3] C.H. Li, S. M. Rohde, On the steady state and dynamic performance characteristics of floating ring bearings, Journal of Lubrication Technology, vol. 103, iss. 3, pp. 389-397, 1981, doi: $10.1115 / 1.3251687$

[4] S.M. Zaharov, V.I. Sirotenko, I.A. Zharov, Work modeling of tribosystem "a crankshaft bearings support of the block of cylinders" of internal combustion engines, Friction and Wear, vol. 16, no. 1, pp. 47-54, 1995.

[5] D. Bonneau, A.M. Chomat, G. Thierry and C. Grente, Influence of the engine block/crankshaft design on the 3D EHD lubrication of a four cylinder inline automotive engine, in 10th World Congress on Theory of Machines and Mechanisms, 20-24 June, 1999, Oulu, Finland, pp. 2488-2495.

[6] D. Bonneau, A.M. Chomat, G. Thierry, C. Grente, $3 D$ EHD lubrication optimised design of a four cylinder in line automotive engine crankshaft, Tribology Series, vol. 38, pp. 391-398. 2000, doi: 10.1016/S0167-8922(00)80143-1

[7] A. Fatu, M. Hajjam, D. Bonneau, An EHD model to predict the interdependent behavior of two dynamically loaded hybrid journal bearings, Journal of Tribology, vol. 127, iss. 2, pp. 416424, 2005, doi: $10.1115 / 1.1866162$

[8] T. Garnier, D. Bonneau, C. Grente, Threedimensional EHD behavior of the engine block/crankshaft assembly for a four-cylinder inline automotive engine, Journal of Tribology, vol. 121, iss. 4, pp. 721-730, 1999, doi: $\underline{10.1115 / 1.2834128}$

[9] D. Bonneau, A. Fatu, D. Souchet, Internal combustion engine bearing lubrication in hydrodynamic bearing, New York: Wiley, 2014.

[10] V.N. Prokopiev, Yu.V. Rozhdestvensky, V.G. Karavaev, E.A. Zadorozhnaya, N.A. Khozeniuk, Dynamics and Lubricant of Piston and Rotor Tribounits. Path. 1. Chelyabinsk: SUSU publishing, 2010.

[11] V.N. Prokopiev, Yu.V. Rozhdestvensky, V.G. Karavaev, E.A. Zadorozhnaya, N.A. Khozeniuk, Dynamics and Lubricant of Piston and Rotor Tribounits. Path. 2. Chelyabinsk: SUSU publishing, 2011.

[12] I.G. Levanov , E.A. Zadorozhnaya, A.L. Dudnikov, Methods of Assessing the Resource of the Crankshaft Bearing of Internal Combustion 
Engine Based on the Calculation of HydroMechanical Characteristics, Tribology in Industry, vol. 37, no. 3, pp. 360-365, 2015.

[13] K. Gavrilov, Y. Goritskiy, I. Migal, M. Izzatulloev, $A$ Numerical Model for Estimation of Service Life of Tribological Systems of the Piston Engine, Tribology in Industry, vol. 39, no. 3, pp. 329-333, 2017, doi: $\underline{10.24874 / \mathrm{ti} .2017 .39 .03 .07}$

[14] P. Kovalenko, S. Perepelkina, T. Korakhanov, Investigation of tribological properties of friction pairs duralumin - fluoropolymer used for design and manufacturing of biomechatronic devices, Tribology in Industry, vol. 39, no. 2, pp. 192-197, 2017, doi: $10.24874 /$ ti.2017.39.02.05

[15] V.N. Prokopiev, E.A. Zadorojznaya, V.G. Karavaev, I.G. Levanov, Improvement of a calculation method of heavy loaded bearings of the sliding greased by non-newtonian oils, Problems of mechanical engineering and reliability, vol. 39, no. 1, pp. 52-55, 2010.

[16] R. Zhang, H. Xueming, S. Yang, X. Li, Perturbation solution of non-Newtonian lubrication with the convected Maxwell model, Transaction of the ASME, vol. 127 , iss. 2, pp. 302-305, 2005, doi: $\underline{10.1115 / 1.1843852}$

[17] I.G. Levanov, The design procedure of characteristic hydromechanical of complex-loaded journal bearings of reciprocator and rotor-type machines lubricated by non-newtonian oils, Vestnik of SUSU, Series Mashinostroenie, vol. 31, no. 258, pp. 34-43, 2011.

[18] V.N. Prokop'ev, A.K. Boyarshinova, E.A. Zadorozhnaya, Multigrid algorithm for integrating the Reynolds equations in dynamic problems concerning slip bearings under complex load, Journal of Machinery Manufacture and Reliability, vol. 34, no. 5, pp. 16-21, 2005.

[19] Y. Rozhdestvensky, N. Khozeniuk, A. Mylnikov, I. Levanov, V. Romanov, Modeling of the main bearings of a multi-supporting crankshaft of the internal combustion engine, in World Tribology Congress, 8-13 September, 2013, WTC-2013, Torino, Italy, pp. 1825-1828.

[20] Y. Rozhdestvensky, N. Khozeniuk, A. Mylnikov, V. Romanov, I. Levanov, Modeling of a multisupporting cranckshaft tribo-system of internal combustion engine, in 15th Nordic Symposium on Tribology, 12-15 June, 2012, NORDTRIB 2012, Trondheim, Norway, p. 163.

[21] A.A. Mylnikov, Experimental research of elastic characteristics of a crankshaft and block case of the four-cylinder in-line engine of ChN 13/15 type, Vestnik of SUSU, Series Mashinostroenie, vol. 271, no. 12, pp. 218-222, 2012. 